\title{
El caballero del Verde Gabán: algunas consideraciones desde el epicureísmo y el estoicismo ${ }^{1}$
}

\author{
JoSEFA ÁLVAREZ*
}

El propósito de nuestro trabajo es abordar la tan estudiada figura del Caballero del Verde Gabán desde la perspectiva de las tradiciones filosóficas epicúrea y estoica ${ }^{2}$ que dejaron una marcada huella en la literatura y el pensamiento de los siglos de oro ${ }^{3}$ y a las que quisiéramos mostrar Cervantes no se mantuvo ajeno. Nos detenemos para ello en la presentación que de sílleva a cabo el caballero [II, 16, pp. 822-23] $]^{4}$ en la que hace gala de una vida acomodada y sosegada que se sustenta en los valores de la prudencia, la piedad y la moderación, para contraponerla seguidamente con la que realiza antes su interlocutor, Don Quijote [II, 16, pp. 820-21].

*. Le Moyne College.

1. El presente trabajo nació como una conferencia para el ciclo Cervantes: Re-Visoes do século XXI que tuvo lugar en Sao Paulo, Brasil, en septiembre de 2003 y que fue organizado por el Instituto Cervantes y el Consulado de España en la misma ciudad. Agradezco las valiosas sugerencias y comentarios recibidos de los profesores Harold G. Jones (Syracuse University) y José M. Lucía (U.C.M.) en su proceso de conversión en este artículo.

2. Obra de referencia fundamental para el estudio de la figura del Caballero del Verde Gabán desde la perspectiva de la tradición filosófica epicúrea es el trabajo del profesor Francisco MárQuEZ VillaNUEVA "El caballero del Verde Gabán y su reino de paradoja" incluido en su libro Personajes y temas del Quijote, Madrid, Taurus, 1975, pp.147-227. En este sentido interesa concretamente el epígrafe que lleva por título "El epicureísmo cristiano", pp. 168-175.

3. Cfr. Allen, Don C., "The rehabilitation of Epicurus and his theory of Pleasure in the Early Renaissance", Studies in Philology, 41 (1944), pp. 1-15; BluHER, Karl A., Séneca en España: Investigaciones sobre la recepción de Séneca en España desde el siglo XIII hasta el siglo XVII, Madrid, Gredos, 1983.

4. Todas las citas del Quijote proceden de la reciente edición de Francisco Rico (Barcelona, Galaxia Gutemberg-Círculo de Lectores, 2004). 
Si, en principio, podría caber la tentación de considerar al del Verde Gabán como un arquetipo, al gusto del humanismo renacentista, del modélico caballero cristiano, muy pronto los críticos han ido más allá a partir de las evocadoras referencias del texto y lo han asimilado a la aurea mediocritas de adscripción neoepicúrea o a la idea del "justo medio" aristotélico 5 . Se ha tratado igualmente de enjunciar su figura en virtud de la minuciosa descripción de su atuendo [II, 16, p. 819], llegando a ver en él a un auténtico libertino cuya baja catadura moral se reflejaría metafóricamente en los colores de aquel $^{6}$.

Desde la perspectiva de la tradición filosófica lo más atinado parece ponerla en relación con los ideales erasmistas que por vez primera rastreara Américo Castro en la obra cervantina durante el primer tercio del s. $\mathrm{XX}^{7}$. El profesor Márquez Villanueva llega a una conclusión semejante en su detallado estudio sobre estos fragmentos vinculando diversos elementos de la moral epicúrea, muy admirada por Erasmo, con la figura de este caballero de verde indumentaria para quien "pesa más la ausencia de vicios que el cultivo de virtudes" y cuya idea de felicidad "se define más bien por la ausencia de la preocupación y el dolor moral que no por sus grandes halagos, triunfos y alegrías"8.

Efectivamente, si hay un aspecto de esta etopeya que pueda hacernos apreciar la huella del pensador de Rótterdam es sin duda la utilización de elementos de la moral epicúrea para describir un modus vivendi caracterizado por situar la felicidad en los ideales de la moderación y la prudencia, así como en el rechazo a la vanagloria.

Pero veamos con detalle de qué modo se da a conocer el caballero a Don Quijote. Observamos como, en primer término, hace mención a su lugar de procedencia y a su estatus para posteriormente presentarse por su nombre [II, 16, p. 822]. Nos enteramos así de que disfruta de una posición holgada a la que, sin embargo, parece restar importancia a través del adverbio "medianamente”. Es aquí donde percibimos un primer eco de la doctrina del Jardín”. En

5. Para una somera revisión de estas y otras interpretaciones, Cfr. MÁRQUEZ VILLANUEva, Op.cit., pp. $160-163$.

6. Cfr. Percas de Ponseti, Helena, Cervantes, the writer and the painter, Columbia, University of Missouri Press, 1988, p. 38. Su postura, presentada ya en otros trabajos anteriores (Cervantes y su concepto de arte, Madrid, Gredos, 1975, vol. 2, p.395) fue en su momento contrarrestada por Gringras, Gerald L. en su artículo "Diego de Miranda, "Bufón” or Gentleman?", Cervantes, 5 (1985), pp.129-140. Apoyándose en minuciosos estudios sobre los trajes de la época concluye que el atuendo del caballero del Verde Gabán coincide con el preferido por los caballeros españoles de la época anterior y contemporánea del autor. En estudios posteriores (BERNIS, Carmen, El traje y los tipos sociales en el Quijote, Madrid, El Viso, 2001) se muestra con rigor que el gabán descrito por Cervantes con tanto detalle correspondería al llamado "gabán lombardo" de los libros de sastrería del XVII, de color verde y el favorito entre los trajes de camino.

7. Cfr. Castro, Américo, El pensamiento de Cervantes, 2a ed. ampliada y con notas del autor y de Julio Rodríguez-PuÉRTOlas, Barcelona-Madrid, Noguer, 1972.

8. Cfr. Márquez Villanueva, Op.cit., p. 169.

9. Ese era el nombre que recibía la escuela que Epicuro funda en Atenas. Véase Diog. Laer. X, 120. Además de las fuentes antiguas recomendamos la lectura de LlEdó, Emilio, El Epicureismo, Madrid, Taurus, 1995, p.32 y García Gual, Carlos, Epicuro, Madrid, Alianza, 1981, pp. 50-53 y 214. 
efecto, bajo la perspectiva de esta, dar importancia desmedida a la riqueza puede ser fuente de perturbación si para obtenerla hubiera que someterse a una actividad desenfrenada. Ello, sin duda, se alejaría del objetivo fundamental de dicha escuela, o sea, alcanzar la felicidad a través de la ataraxia:

Muchos que obtuvieron riquezas no encontraron en ellas la liberación de sus males, sino un cambio de estos por otros mayores [fr. 479 Us. ${ }^{10}$

La riqueza, en el ideal epicúreo, ha de concebirse no tanto bajo el término material de "poseer más" como el de "limitar los deseos" aprendiendo a desprenderse de aquellos que son superfluos. Y esta parece ser la elección del del Verde Gabán al decirnos, poco después, que practica la caza, afición acorde a su categoría social, pero no mantiene "ni halcón ni galgos sino algún perdigón manso o algún hurón atrevido" [II, 16, p. 823], animales estos últimos más sencillos y carentes del porte de los primeros ${ }^{11}$. Sería un ejemplo del principio de autarquía que no supone tanto el desprecio por la abundancia como el saber contentarse con poco cuando ella llegue a faltar ${ }^{12}$.

No obstante, admitida la idea de que la felicidad se obtiene a través de la limitación de los deseos, si el azar nos depara algún bien, no hemos de despreciarlo, sino aceptarlo como un placer gratuito que este nos proporciona:

La Naturaleza nos enseña a considerar insignificantes las concesiones de la Fortuna, a no valorarla en exceso. Nos enseña también a aceptar con serenidad los bienes deparados por el azar y a mantenernos firmes ante lo que parecen ser sus males. Porque efímero es todo bien y todo mal estimado por el vulgo y la sabiduría nada tiene que ver con la Fortuna [Ep., fr. 489 Us.]

De ahí que el caballero pueda gozar "alguna vez" de comidas en compañía de sus vecinos y amigos, siendo sus convites "limpios y aseados y nonada escasos" [II, 16, p. 823] porque, como el propio Epicuro recuerda, habituarse a una vida sencilla permite gozar más de la opulencia cuando se presenta. Y, ya que la fortuna le ha brindado tal posibilidad, D. Diego disfruta de dicha opulencia "alguna vez", insistiendo de nuevo en la idea de la mesura.

El ideal de autosuficiencia que implica el dominio de los deseos lo hace extensivo esta escuela a diferentes ámbitos, empujando a la búsqueda de la vida retirada, de cuyo mejor ejemplo nos sirve el Jardín, donde Epicuro convivía con sus discípulos y amigos ${ }^{13}$. Fiel también al mismo aspecto se presenta Don Diego como un hombre que pasa su vida "con su mujer e hijos y con sus ami-

10. Las citas de los textos de Epicuro proceden de la edición de Montserrat Jufresa (Madrid, Tecnos, 1991).

11. Estas líneas han sido sometidas a dispares lecturas. Cfr. PERCAS DE PONSETI, Helena, Cervantes y su concepto de arte, Madrid, Gredos, 1975, vol. 2, p. 337, donde la autora ve en la caza con trampa un indicio de la falsa condición de caballero del del Verde Gabán.

12. Estas ideas las pone claramente de relieve Epicuro a lo largo de su Carta a Meneceo.

13. Cfr. Nota 8. 
gos" [II, 16, pp. 822-23]. En el afán de lograr una vida sencilla, libre de preocupaciones que alteren el espíritu, don Diego no da muestras de participar en ningún ámbito de la vida pública. El epicúreo es bien firme en este punto y propugna el distanciamiento de la política. Ni ocupará cargos ni se dedicará a los negocios, requisito imprescindible para el autogobierno, para la verdadera autarquía $^{14}$, según nos cuenta el propio fundador de la escuela:

La felicidad y la dicha no las proporcionan ni la cantidad de riquezas ni la dignidad de nuestras ocupaciones ni cargos y ciertos poderes, sino la ausencia de sufrimiento, la mansedumbre de nuestras pasiones y la disposición del alma que delimita lo que es acorde a la Naturaleza [Ep., fr. 548 Us.]

El apartarse de la vida pública no está reñido, no obstante, con algún trazo de amor al prójimo ni con el reconocimiento de la amistad como la mayor fuente de felicidad para el individuo:

De los bienes que la sabiduría procura para la felicidad de una vida entera, el mayor con mucho es la adquisición de la amistad [Ep., Máximas Capitales 27] ${ }^{15}$

Y así como Epicuro elige limitarse a un marco social más reducido, el de la comunidad de amigos, del mismo modo vemos a D. Diego retirado del mundanal ruido y volcado en los suyos.

La moderación del personaje alcanza incluso a la posesión de libros. Nos dice que de ellos tiene "hasta seis docenas" [II, 16, p. 823], unos en romance y otros en latín y de tema variado (si bien no de caballerías), de entre todos los cuales se inclina por los de entretenimiento. No nos deja duda el autor de que no estamos ante un erudito y puede vincularse así el personaje a la idea epicúrea de que la felicidad del individuo no se fundamenta en la paideia, ya que aquella no va ligada a la sabiduría sino al placer concebido como ausencia de dolor y turbación. La paideia resulta ser en la vida sólo mera distracción. "De cualquier educación, hombre feliz, huye desplegando la vela más rápida" [Ep., fr. 163 Us. $]^{16}$, nos recomienda Epicuro. Y esa parece la opción de nuestro caballero para quien la lectura no tiene tanto un valor educativo como de mero pasatiempo.

Llegamos a la última parte de la presentación de Don Diego donde son las ideas de la prudencia y la piedad las que ocupan un lugar destacado. En las primeras líneas "ni gusto de murmurar, no escudriño las vidas ajenas" [II, 16,

14. Sobre este tópico véase GARcía GuAL, Op.cit., pp. 63-67 y 192-193. Cfr. p.69: "Los epicúreos no rompen las amarras con la ciudad de modo absoluto, pero limitan su colaboración para disminuir al mínimo los riesgos de esta dependencia".

15. Cfr. Ep., fr. 541 Us.: "La amistad no puede separarse del placer y por este motivo ha de ser cultivada porque sin ella no puede vivirse con seguridad y sin miedo, ni siquiera puede vivirse alegremente".

16. Sobre el nulo valor que Epicuro concedía a la paideia o educación tradicional, véase LLEDó, Op.cit., pp. 129-135; García GuAL, Op.cit., pp. 59-62. 
p. 823], el caballero se mantiene fiel a la idea epicúrea de verse libre de las perturbaciones del alma, puesto que la murmuración sólo puede reportar inquietud al que la practica.

Por otro lado, en la frase "reparto mis bienes con los pobres" [II, 16, p.823], retomamos la idea de la autosuficiencia, ya que desde ese valor (como los propios epicúreos manifiestan) se permite compartir con los otros lo que le sobra y ser generoso:

Confrontado el sabio a la necesidad, sabe más dar que tomar para sí; tal es el tesoro de autosuficiencia que ha obtenido [Ep., Sentencias Vaticanas, 44]

Y todo ello "sin hacer alarde de las buenas obras" [II, 16, p. 823], por no dar entrada en su corazón a la hipocresía y la vanagloria, lo que se acomoda bien al principio "pasa desapercibido mientras vivas"17. Es cierto que el epicúreo no rehuye la estima de los demás, aunque sólo sea por razones de utilidad, para lograr una mayor seguridad personal, pero sin dedicar a ello ni gran interés ni mucho tiempo:

Es conveniente que nos acompañe espontáneo el elogio de los demás, pero nosotros debemos ocuparnos de la salud del alma [Ep., Sentencias Vaticanas, 64]

El tema que concluye la etopeya es el de la piedad hacia la divinidad que en este caso se asimila, por supuesto, al monoteísmo cristiano en su culto a "Dios Nuestro Señor" y a la Virgen María.

Si bien Epicuro tradicionalmente fue considerado el primer ateo de la historia por su negación de la Providencia divina y fue vilipendiado por ello durante el Medioevo ${ }^{18}$, lo que las fuentes testimonian es, por el contrario, su creencia en los dioses. Cierto es que concibe una nueva forma de relación con la divinidad al considerar que los dioses no se ocupan de los asuntos humanos, pero no por ello presupone que debamos olvidarnos de su existencia. Bien al contrario, la piedad, entendida como veneración alegre que nos lleva a contemplar la perfecta felicidad de los dioses, sin por ello esperar nada a cambio, revierte goce y alegría en nosotros. El epicúreo llama a los sabios "amigos de los dioses" y para aquellos "el bien más elevado es contemplar el esplendor de los dioses. No tienen nada que pedirles y, sin embargo, les rezan... A este respecto se puede hablar de "puro amor", de un amor que no exige nada a cambio"19.

17. Cfr. García Gual, Op.cit., p.193.

18. Sobre la visión negativa de la figura de Epicuro en el Medioevo véase Quevedo, Francisco de, Defensa de Epicuro contra la común opinión. Edición crítica a cargo de Eduardo Acosta. Madrid, Tecnos, 1986, pp. Xxv-Xxxviii.

19. ANTOLÍN SÁNCHEZ, Javier, Influencias éticas y sociopolíticas del epicureismo en el Cristianismo primitivo, Tesis doctoral, Alicante, Biblioteca Virtual Miguel de Cervantes, 2002, p. 372. Cfr. en este sentido Filodemo, fr. 386 Us. 
A lo que Epicuro se opone es a la burda visión que de los dioses posee el vulgo, pero, por lo demás, admite que se les debe hacer sacrificios:

Sacrifiquemos, pues, piadosa y rectamente como conviene, y cumplamos con todas las demás cosas de acuerdo con las leyes, sin dejarnos turbar por las vanas opiniones acerca de los seres más perfectos y augustos [Ep., fr. 388 Us.]

Interpretando, pues, en su justo sentido semejante visión de la religiosidad, es plausible que igualmente este rasgo del caballero se rescate de la doctrina del Jardín acomodándolo al dogma cristiano.

En este retrato de Don Diego, como vemos, se confunden el perfecto epicúreo y el caballero cristiano. La cuestión es cómo se llega a dicha confluencia. Desde sus primeros textos Erasmo impulsa a través de su obra una visión positiva de Epicuro $^{20}$, pero es en el coloquio que lleva por título El Epicúreo ${ }^{21}$ donde el sincretismo entre epicureismo y cristianismo se advierte plenamente. En él sus protagonistas, Hedonio y Spudeo, mantienen una conversación en la que el primero pretende mostrar a toda costa a su interlocutor el carácter cristiano de las principales tesis epicúreas. Tanto es así que aquel, desde cuya voz Erasmo lleva a cabo la defensa de la secta, dice abiertamente que "no hay epicúreos más auténticos que los cristianos que viven piadosamente" e incluso llega a admitir que "nadie merecería mejor el título de epicúreo que el adorable fundador de la doctrina cristiana pues sólo él nos ofreció la existencia más dulce y la más llena de verdadero placer" [El Epicúreo pp.308-309].

Ahora bien, ¿cómo llega Erasmo a ese gran respeto por un filósofo vilipendiado por los Padres de la Iglesia, pese al reconocimiento que manifestaron estos de la bondad de su doctrina de la autarquía y del espíritu ecuménico de su pensamiento ${ }^{22}$ ? Erasmo fue traductor y admirador de los textos de Séneca y en este estoico romano encontramos muchas veces a Epicuro como ejemplo. De tal admiración puede proceder su empeño firme en hacer de Epicuro un estoico, lo que resulta evidente en el coloquio antes citado. No es de extrañar, entonces, que Cervantes, si fue el gran conocedor de la obra del de Rótterdam que un sector tan importante de la crítica cervantina póstula ${ }^{23}$, siga la línea de este en su descripción del del Verde Gabán pues también en ella se mezclan con los epicúreos algunos rasgos estoicos. Veámoslos con detalle.

20. Sobre el epicureismo cristiano de su opúsculo juvenil De contemptu mundi véase VILLACAÑAS Berlanga, José L., "Del desprecio del mundo: el De contemptu mundi de Erasmo", (2004) Respublica Hispana, Biblioteca Virtual del Pensamiento Político Hispánico Saavedra Fajardo, Universidad de Murcia. [http://saavedrafajardo.um.es/BIBLIOTECA/IndicesW.nsf/FResPuHis?Openform]

21. Rotterdam, Erasmo de, Colóquios, Ed. y traducción de Pedro R. Santidrián, Madrid, EspasaCalpe, 2001.

22. Cfr. Acosta, Op.cit., p. xxiv.

23. Recuérdese al citado Américo CASTRo (Cfr. Nota 6), pionero en este aspecto de la crítica cervantina, o el importante trabajo de Bataillon, Marcel, Erasmo y España, 2 vols., México, FCE, 1950. 
La alusión a la familia, al hecho de considerarla elemento de "tranquilidad" en la vida, es más afín al estoicismo que al epicureismo. Epicuro distinguía el amor del sexo y consideraba que el primero era siempre fuente de inquietud. El segundo se trataba, por el contrario, de una necesidad natural y como tal había que satisfacerla sin volcarse, no obstante, en su disfrute. El matrimonio podía producirse en algún momento de la vida de especial dificultad, pero sólo por "utilidad" 24 . Sin embargo, para los estoicos que consideran el objetivo de la existencia "vivir conforme a la naturaleza", perseguir el afecto familiar, la salud, la belleza... está dentro de la naturaleza humana. Todos ellos son bienes "preferibles" naturalmente a sus contrarios, aunque el auténtico bien resida en el ámbito propio de la actividad del hombre, el moral, la adquisición de la virtud. Admiten que el ser humano es social por naturaleza y que es por ella por la que se asocia para la comunidad política ${ }^{25}$. Insistiendo en esa línea, Cicerón se manifiesta así sobre la unión marital:

Desde el momento en que observamos que el hombre ha nacido para proteger y salvaguardar a sus semejantes, corresponde a la naturaleza que el sabio (...) quiera unirse a una esposa y tener hijos [Cic., De finibus, III, 68]

En cuanto a la moderación en la posesión de libros, recibimos aquí también los ecos de Séneca, que en la segunda de sus Cartas a Lucilio habla de la abundancia de libros como fuente de dispersión ${ }^{26}$. La diferencia radica en que para Séneca la lectura era una forma de enriquecimiento del alma, de acceso a la virtud. Aconseja a su amigo que se fije sólo en determinados pensadores para lograr que alguna cosa permanezca efectivamente en su espíritu.

Un aspecto de la presentación del caballero donde más evidente es la huella estoica es el de la moderación a la hora de hablar sobre los demás y juzgarlos. Hallamos textos muy significativos al respecto en el Enquiridión de Epicteto $^{27}$ que fue obra de estudio y traducción del propio Erasmo:

Fíjate ya desde ahora un carácter y un ideal de conducta, al cual te mantendrás fiel ante ti mismo y cuando te halles entre los demás hombres. Para empezar, haya de ordinario silencio o háblese lo necesario y con brevedad... $\mathrm{y}$, sobre todo, no hables de la gente reprendiendo o alabando o haciendo comparaciones [XXXIII, 2]

24. Cfr. García Gual, Op.cit., p. 221.

25. Cfr. Cic., De finibus, III, 66: “... sic inter nos natura ad civilem communitatem coniuncti et consociati sumus". Los fragmentos citados de esta obra de Cicerón (De finibus bonorum et malorum) proceden de la edición bilingüe latín-inglés realizada por H. RACKHAM (Cambridge, Massachussets, Harvard University Press, 1951). Las traducciones al español son de la autora del artículo.

26. SenecA, Lucio Anneo, Ad Lucilium Epistulae morales, London-New York, Loeb Classical Texts, 1917. Cfr. I, 2, 2: "Illud autem vide, ne ista lectio autorum multorum et omnis generis voluminum habent aliquid vagum et instabile".

27. Las citas en traducción al español de esta obra se han tomado de la edición de José Manuel GARCÍA DE LA Mora (Barcelona, Anthropos, 1991). 
En opinión de Epicteto, el sabio, el que dedica su vida a la filosofía y progresa en esta, "a nadie censura, a nadie alaba, de nadie se queja, nada dice de sí como si fuera alguien o supiera algo" [XLVIII, 2].

Pero es en las frases "oigo misa cada día y soy devoto de nuestra Señora y confío en la misericordia infinita de Dios nuestro Señor" [II, 16, p. 823] donde pesa más la presencia estoica que la epicúrea. Para los estoicos, el Logos universal que anima el cosmos es la única representación auténtica de la Divinidad. El Logos, Dios, es el alma del mundo al que mantiene, penetra y vivifica. Este monoteísmo que identifica a Dios con el alma del mundo, fue bien grato a los Padres de la Iglesia frente a la negación de la Providencia epicúrea.

Por otro lado Séneca nos advierte que la fama y la ostentación propia no acercan al hombre a Dios. Poseer un alma buena es lo que realmente con él lo identifica ${ }^{28}$ a la par que realizar buenas obras y no alardear de ellas a través de la palabra. Nuestra palabra tiene que estar de acuerdo con nuestra vida según Séneca ${ }^{29}$. De ahí que don Diego no quiera "hacer alarde de las buenas obras" [II, 16, p. 823]. Las obras son la manifestación externa de la virtud interna. En Cervantes esta idea es de vital importancia y recorre toda su producción las más de las veces en boca de Don Quijote. El mayor elogio que este puede hacer de su amada Dulcinea es que "es hija de sus obras" [II, 32, p. 980]. De manera contundente manifiesta en algún momento "es muerta la fe sin obras" [I, 50, p. 626]. Se trata de una idea estoica que recogió el tomismo escolástico y que se enarboló en Trento frente a la teoría contraria del luteranismo ${ }^{30}$.

Una de esas buenas obras de las que se precia el Caballero del Verde Gabán es la de "procurar poner paz entre los desavenidos" [II, 16, p. 823]. Mientras un epicúreo no alteraría ni un segundo su espíritu con semejante propósito, el componente de solidaridad que caracteriza la doctrina estoica reivindicaría dicho comportamiento. Y nos sirven como ejemplo en este sentido las palabras de Marco Aurelio cuando nos empuja diciendo "Reverencia a los dioses y protege a los hombres. Breve es la vida. El solo fruto que se puede sacar de esta existencia terrestre son las santas disposiciones del ánimo y las acciones sugeridas por el bien común" [VI, 30] ${ }^{31}$. Tenemos obligaciones con los otros seres humanos y entre ellas, por qué no, la de evitar desavenencias.

28. Cfr. en este sentido Sen. I, XXXI, 10-11: Parem autem te deo pecunia non facet; deus nihil habet. Praetexta non faciet; deus nudus est. Fama non faciet nec ostentatio tui et in populos nominis dimissa notitia; nemo novit deum... Quaerendum est, quod non fiat in dies eius, quoi non posit obstari. Quod hoc est? Animus, sed id rectus, bonus, magnus.

29. Sen., Epist. ad Luc., I, LXXV, 4: "Concorde sermo cum vita".

30. Sobre el tema de las "buenas obras" véase GARROTE, Francisco, La naturaleza en el pensamiento de Cervantes, Salamanca, Univ. de Salamanca, 1997, p.152. El tema reaparece en significativos fragmentos de El Quijote como en estas palabras de Sancho en el cap. XX de la segunda parte: "Bien predica quien bien vive". En Maravall, José A., Utopía y contrautopía en el Quijote, Santiago de Compostela, Editorial Pico Sacro, 1976, p.85, nota 5, se vincula esta idea a Trento, si bien el autor la considera común al pensamiento español de la época y llegada a él incluso por otras vías.

31. Marco Aurelio, Meditaciones. Prólogo de Carlos García Gual. Versión castellana de Miguel Dolç, Madrid, Debate, 2000. 
De cualquier manera, son los valores epicúreos los que destacan en la figura del caballero y nuevamente así lo percibimos cuando, avanzado algo el capítulo, nos habla de la afición de su hijo a la poesía con un gran desagrado, que no es otro que el que el mismo Epicuro sentía por ella, según lo transmite Diógenes Laercio. En abierto contraste, el estoico discurso de Don Quijote, defensor del ideal de los Studia Humanitatis que sitúan a la poesía como corona de ciencia, pidiendo al caballero que "deje caminar a su hijo por donde su estrella le llama" [II, 16, p. 827], o sea, le deje seguir su inclinación natural, lo que la Naturaleza le ha preparado para hacer. Y enfatiza aún más su ascendente ideológico al añadir que "si el poeta fuere casto en costumbres, lo será también en sus versos; la pluma es la lengua del alma” [II, 16, p. 828]. Así pues, hay que seguir a la Naturaleza y actuar siempre con discreción, manifestando esa máxima en cualquier aspecto de la vida al que el destino nos conduzca.

A partir de este momento observamos una cada vez más clara contraposición entre ambos personajes que se sustenta en las diferencias de dos doctrinas filosóficas que se tocan en puntos importantes, pero que divergen en lo fundamental. Don Quijote insiste en acogerse a la estoica noción de destino cuando al presentarse al del del Verde Gabán aduce que ser caballero andante es lo que le "cupo en suerte" y que no puede por eso "dejar de acometer todo aquello que a mí me pareciere que cae bajo la jurisdicción de mis ejercicios" [II, 17, p. 840]. Ateniéndose a ella enfrenta la aventura de los leones ante la que Don Diego hace gala de su epicúrea prudencia y de su intención de evitar el dolor físico al huir del enfrentamiento con estos animales y al aconsejar así a Don Quijote:

Señor caballero, los caballeros andantes han de acometer las aventuras que prometen esperanza de salir bien dellas, y no de aquellas que en todo la quitan [II, 17, p. 832]

Dicho consejo será ignorado por un Don Quijote dispuesto a soportar cualquier dolor y que ejemplifica el ideal estoico de la apatía, esto es, aceptar el destino y dominar las pasiones como medio para alcanzar la virtud:

Ahora, venga lo que viniere, que aquí estoy con ánimo de tomarme con el mesmo Satanás en persona [II, 17, p. 831]

Para realzar el contraste ya patente entre uno y otro personaje, Cervantes concluye la aventura en el capítulo XVIII con la llegada de su audaz protagonista a la morada del del Verde Gabán donde será sorprendido por un "maravilloso silencio". En él Don Quijote hallará un momentáneo remanso de paz a su vida entregada a la acción pero, tras cuatro días de "regaladísima" estancia en la casa, decide proseguir su camino para "cumplir con su oficio por no parecer bien que los caballeros andantes se den muchas horas al ocio y al regalo" [II, 18, p. 851]. Sin duda Don Quijote refuerza a través de sus palabras la clara oposición entre su activa vida y la a su juicio ociosa de su anfitrión. Don 
Diego, por su parte, se acerca aún más al ideario vital epicúreo a través de este silencio que interpretamos como marco idóneo para hallar el placer, placer que se asimila a la paz de espíritu que proporciona el reposo ${ }^{32}$.

En conclusión, si bien Don Diego de Miranda es reflejo de un sincretismo de ideas de procedencia estoica adaptado, la mayoría de las veces, al dogma católico de la época al más puro estilo erasmista, por encima de todo encarna a través de su "vida regalada" el ideal epicúreo de felicidad definido como ausencia de dolor (aponía) o de turbación (ataraxia). Frente a él se alza un Don Quijote, ejemplo de apatía estoica, que soporta con rigor lo que la Naturaleza ha dispuesto para su persona, convencido de que con sus valerosas y continuas obras dará clara muestra de su virtud interior; un hombre de acción que se niega al estatismo epicúreo, al ideal de ataraxia que conduce a una vida derrotista y limitada ${ }^{33}$; un Don Quijote que reacciona ante la falta de inquietud intelectual que manifiesta abiertamente el caballero (uno de los pocos personajes leídos que aparecen en la segunda parte del libro que desconoce la existencia de la primera) y que se impone a un ideal de vida que le sigue resultando sospechoso con respecto a su postura ante Dios:

Preguntóle don Quijote que cuántos hijos tenía, y díjole que una de las cosas en que ponían el sumo bien los antiguos filósofos, que carecieron del verdadero conocimiento de Dios, fue en los bienes de la naturaleza, en los de la fortuna, en tener muchos amigos y en tener muchos y buenos hijos [II, 16, p. 824]

Cervantes se sirve de dos doctrinas filosóficas bien presentes en el ambiente cultural de la época para oponer a través de estos personajes dos modos de vida en conflicto. Por un lado, el ideal caballeresco medieval que se halla en extinción, próximo al estoicismo en la idea de seguir lo que la Naturaleza dispone, basado en un profundo individualismo político y jurídico, que será penetrado poco a poco del antropocentrismo renacentista ${ }^{34}$. Por otro, un nuevo caballero, asimilado al ideal vital epicúreo, que "no ha ejecutado nunca la

32. MÁRQUEZ VillanUEVA resalta el valor de este silencio como elemento de contraste entre ambos personajes e indica que aquel sólo sirve al caballero para "dormir apaciblemente la siesta". Cfr. Op.cit., p.159.

33. Don Quijote coincide en ello con la opinión de Séneca que, a pesar de rehabilitar a Epicuro en tantas ocasiones, consideraba dicho ideal como vida tranquila y mar de muertos. Cfr. Epist. ad Luc. I, LXVII, 14: "Hoc loco mihi Demetrius noster occurrit, qui vitam securam et sine ullis fortunae incursionibus mare mortuum vocat". Recordemos que los estoicos más afamados tuvieron una vida política muy activa (Séneca, Cicerón, el emperador Marco Aurelio) hecho que los contrapone radicalmente a los epicúreos.

34. Véase en este sentido Maravall, Op.cit., p. 56: "El representante del viejo espíritu caballeresco rechaza, porque no puede ni siquiera comprenderla, la situación política nueva, en la que a determinadas personas, y no a otras, se les constituye en función pública, para la cual son ellas las competentes". Por otra parte, considera que el personaje de Don Quijote es concebido inicialmente por su autor como un imitador de caballero andante "que más tarde se presenta con toda una gran misión... reformadora que individualiza su carácter, que le proporciona personalidad, hasta convertirlo en "un producto de ese "descubrimiento del hombre individual" propio del Renacimiento" (p.84). 
menor caballería"35, que se ocupa de la mera administración de su hacienda y vive una vida tranquila, y que quizá sea la semilla de la nueva clase social emergente a raíz de la aparición de un estado moderno cada vez más burocratizado frente a cuya soberanía el individuo nada puede ${ }^{36}$.

Existe la posibilidad de que Cervantes haya llegado a estas doctrinas a través de exempla ampliamente difundidos en el ambiente cultural de la época, pero es bien factible que las conociera, según hemos visto, gracias a las lecturas de Erasmo o incluso de otros humanistas de la época ${ }^{37}$. No obstante, no podemos descartar una lectura directa de los propios clásicos, especialmente de Séneca, al que Anthony Close cita entre los autores a los que pudo acceder como alumno del Estudio de la Villa de Madrid regentado por López de $\operatorname{Hoyos}^{38}$ y de quien puede proceder el sincretismo de ideas que encontramos en nuestro personaje cervantino. Epicuro es para Séneca modelo de frugalidad y mesura ${ }^{39}$, sobre todo en el aspecto del desprecio por la fama, así como ejemplo de hombre libre carente de temore ${ }^{40}$, virtudes ambas bien puestas de realce en el fragmento cervantino. Por otra parte, Cervantes, que igualmente cultivó la poesía y estaría bien familiarizado con la lírica de su tiempo, pudo incluso recibir de esta la conjunción de ideas de ambas escuelas filosóficas procedente a la sazón de la imitación de Horacio y presente en tópicos como la vida retirada, la paz del alma y la indiferencia ante los bienes materiales y las pasiones $^{41}$.

Epicureismo y estoicismo parecen ser usados conscientemente por nuestro autor a través de uno y otro personaje para presentar un litigio entre dos mundos, uno en extinción y otro en auge, del que aquel, que publica esta parte de su obra con el comienzo de un nuevo siglo, fue testigo excepcional. Al mismo tiempo, ambas doctrinas permiten a Cervantes realizar un contraste entre dos

35. Cfr. Márquez Villanueva, Op.cit., p. 176: "El caballero del Verde Gabán no ha ejecutado nunca, como es lógico, la menor caballería. De ahí que ni siquiera lleve espada, sino un romántico alfanje morisco, un arma de opereta, puramente decorativa."

36. Sobre la oposición estado moderno y viejo espíritu caballeresco véase MARAVALL, Op.cit., pp. 52-54.

37. En torno a la revalorización de la doctrina epicúrea en la obra de el Pinciano y de otros humanistas de la época Cfr. AcostA, Op.cit., p. xliii.

38. Véase "Cevantes: Pensamiento, personalidad, cultura" en CERvanTEs, Miguel de, El ingenioso hidalgo Don Quijote de la Mancha, Ed. Francisco Rico, Barcelona, Galaxia Guttenberg, 2004, vol. 2, p. 1xxv. No obstante, Alfredo Alvar EZQUERRA, en una recién publicada biografía sobre el autor, relativiza el papel de la escuela de López de Hoyos en la educación de Cervantes y considera que no hay que perder de vista ni su autodidactismo ni la influencia en su formación de sus amigos escritores. Cfr. Cervantes: genio y libertad, Madrid, Temas de hoy, 2004, cap. 2.

39. Cfr Sen., Epist. ad Luc., I, XXI , 7-8; I, XX, 9-11.

40. Cfr. Sen., Epist. ad Luc., I, LXXV.

41. Acosta (Op.cit., p. xliv) identifica ecos epicúreos y estoicos en los versos de la época cuando se presenta el ideal de la tranquilidad del alma, aquel que caracteriza al sabio alejado de cualquier cosa que lo turbe, y cita ejemplos de las epístolas versificadas entre Diego Hurtado de Mendoza y Juan Boscán: "Yo, Boscán, no procuro otro tesoro/ sino poder vivir medianamente/ ni escondo riquezas ni la adoro". Obsérvese el uso del significativo adverbio medianamente que también Cervantes pone en boca de su personaje. 
concepciones de la existencia diametralmente opuestas: idealista y utópica la una, a la búsqueda de una perdida edad de Oro; de marcado carácter racionalista la otra, al aceptar sin posible cuestionamiento la realidad circundante ${ }^{42}$.

\title{
Resumen
}

El propósito de nuestro trabajo es abordar la figura del Caballero del Verde Gabán desde la perspectiva de las tradiciones filosóficas epicúrea y estoica que dejaron una marcada huella en la literatura y el pensamiento de los Siglos de Oro. Para ello se han rastreado algunas fuentes grecorromanas que nos han llevado a determinar que en aquella confluyen rasgos de ambas doctrinas con evidente predominio de la epicúrea, en contraste con un Don Quijote de clara adscripción estoica. Tratamos, finalmente, de demostrar como a través de dichas doctrinas, similares en algunos aspectos pero opuestas en otros fundamentales, Cervantes presenta al lector dos modos de vida en pugna al comienzo de un nuevo siglo: uno, realista y pragmático, ejemplificado en el del Verde Gabán, que emerge con fuerza imparable; otro, el quijotesco, con su anacrónico idealismo en inevitable decadencia.

Palabras clave: Caballero del Verde Gabán - Tradiciones filosóficas estoica y epicúrea

\begin{abstract}
The purpose of this paper is to study the figure of the "Caballero del Verde Gabán" from the perspectives of the stoic and Epicurean philosophic traditions given that these traditions deeply influenced the literatures and thought of the Golden Age. To do so, we search and analyze several greco-roman sources that lead us to determine that although both philosophic traditions converge in the figure of the "Caballero del Verde Gabán" a clear preeminence of the epicurean tradition is evident. In contrast, a clear stoic tradition is clear in the figure of "Don Quijote". We attempt to show how Cervantes presents the reader with two ways of life at odds with each other at the beginning of a new century; one full of realism and pragmatism in the figure of the "Caballero del Verde Gabán", the other, "the quijotesco" showing its anachronistic idealism.
\end{abstract}

Key Words: "Caballero del Verde Gabán" - Stoic and Epicure philosophic traditions.

42. Recordamos al respecto la conclusión del profesor MÁRQuEZ VillanUEVA: "La verdadera diana contra la que aquí se apunta no es tanto la flor delicada del epicureismo cristiano como la base de racionalismo que tras ella se perfila. (...) ¿Qué ocurrirá cuando gentes tan cuerdas como Don Diego de Miranda empuñen el gobernalle?" Es esta última la pregunta que entiende perfila Cervantes a través de nuestro personaje. 